\title{
Problems of residential migration in the framework of the formation of "smart agglomeration"
}

\author{
Aidar Asylbayev ${ }^{1}$, Kunduzkul Niiazalieva ${ }^{2}$, Natalia Brovko $^{1}$, and Malik Borbugulov ${ }^{3, *}$ \\ ${ }^{1}$ SEIHPE Kyrgyz-Russian Slavic University named after the first President of the Russian Federation \\ B. N. Yeltsin, Bishkek, Kyrgyz Republic \\ ${ }^{2}$ Educational institution autonomous non-profit organization of higher education "Kyrgyz-Russian \\ Academy of Education", Bishkek, Kyrgyz Republic \\ ${ }^{3}$ Ala-Too International University, Bishkek, Kyrgyz Republic
}

\begin{abstract}
The relevance of the work is in solving problems arising from the disproportionate development of migration flows and natural and technical resources. The paper examines the development of migratory residential areas in the context of the need to form an integral system of smart satellite cities around the capital - Bishkek city. There is also a study of the environmental and social problems that arise due to the lack of a systematic approach to the management of the city and its satellites. The existing today, numerous individual housing buildings around the capital cause a serious problem for the rational use of environmental and engineering resources and balanced demographic development of the whole country. To solve the impending problems, it is recommended to build a fundamentally new model of an urban and environmentally friendly agglomeration. Thus, the purpose of the article is to identify problems among new immigration residential buildings and rationale for the need to build city-forming "smart zones of urban development" with a control center in Bishkek. Conclusions and recommendations are given for the government and administrative services of the Kyrgyz Republic.
\end{abstract}

\section{Introduction}

Nowadays, the world is facing not only with the problem of the quantity of housing, but also with the necessity of building environmentally friendly, safe and affordable housing. There is no secret that the global trend is the concept of "environmentally friendly, safe and smart city", which is aimed at increasing the level of environmental safety and comfort of living for all segments of the population in cities of different scale and purpose. For example, the presence of green areas, undeveloped spatial areas, smart housing and transport systems help to improve the health and safety of the population and protect people's interests from various of risks and threats.

There is a big problem for the Kyrgyz Republic, which is a high and active internal migration to an economically developed region, Chui oblast, where the capital of the country,

${ }^{*}$ Corresponding author: malik.borbugulov@alatoo.edu.kg 
Bishkek, is located. It is obvious that such migration will predict the formation of demand for real estate, and first of all for land plots for individual housing construction. It is necessary to take into account that these plots are belonged to green zones or agricultural zones with high quality land. It is worth noting that at current conditions the internal migration is represented by residents moving to Bishkek from the rural areas of the southern region. Internal migration is present in many countries, where compatriots from rural settlements move to urbanized cities with a high demand for labor. Such picture of the internal movement of the population is a natural internal migration process. However, it should be taken into account that the excessive level of internal migration shows the disproportionate economic development of the regions of the country. The world practice shows that it often leads to an excessive overpopulation of capital and business cities.

In our case, overpopulation should be understood not as an excessively large accumulation of newcomers, but as the failure of the city to provide a decent environmental condition, engineering and social services and other infrastructure services to new individual developers. At the same time, migration residential areas quite successfully solve the demographic problem of big cities, a small birth rate among the local urban population. As a result, the absence of an influx of population, causes a shortage of labor resources for the functioning of the city itself.

The relevance of the article at the time of the active influx of the population is beyond doubt. The unorganized appearance of housing estates and, at the same time, the unorganized registration of the population in them leads to the adoption of inadequate management decisions on the provision of engineering and other infrastructure communications. Without knowledge about the exact size of the population and the density of residence in new individual buildings the state is unable to provide this population with social facilities in a decent amount. Also, the lack of legal status, due to the absence of registration, creates additional barriers to the successful development of a smart city. Not managed migration residential areas around the capital can cause a disproportionate demographic growth of the population. In particular, such migration leads to the appearance of regions with demographic failure and abandoned settlements, which, in turn, create additional economic and environmental problems.

In that regard, the authors' assertion that the problems of active growth of individual new buildings have led to the fact that the capital cannot adequately adapt to the large influx of internal migrants is true. Therefore, an undeveloped infrastructure and the absence of basic conditions for life, new immigration buildings eventually become the center of environmental pollution and social injustice with a high percentage of dissatisfaction with the country. Thus, the social problems, accumulated over the years and unresolved in time, of internally displaced people contribute to the intensification of the already exacerbated social tension in the society [1].

The purpose of the article is the identification of problems among new residential buildings of internal new immigrants and justification of the need to build city-forming "smart belts of urban development" with a control center in Bishkek.

Analysis of the latest international and domestic publications. Foreign studies concerning migration and the housing issue of migrants include the works of the following authors: C. H. Mulder (2006, 2009) [2; 3], T. De Vroome (2010) [4], F. Van Tubergen (2010) [4], Thomas J . Cooke (2009) [3].

In the process of preparing the article, the following researches of Russian and domestic scientists related to the problems of housing and demographic development of the country were studied: A. N. Asaul. [5; 6], K. Isaeva [7], S. Borsokbaeva [7], G.V. Kumskova [8], K. N. Niyazalieva [8], R. B. Salmorbekova [9], N. A. Israilova [9], U. Zh. Ergeshbaeva [10], etc. 


\section{Materials and methods}

It should be noted that the fact of identifying the connection between housing problems and urbanization of the population will make it possible to form an effective unified demographic and housing strategy within the framework of the development of "smart" cities and environmentally friendly satellite cities. At the same time, the improvement of the housing situation among the citizens of Kyrgyzstan creates the foundation for the development of positive dynamics of demographic processes by eliminating or minimizing factors, including environmental ones, that have a negative impact on the dynamics of reproduction and migration of the population.

Based on the foregoing, the research methodology of the topic was based on general methods of systematizing information, analysis and synthesis, methods of classifying and isolating information, as well as methods of survey data analysis on the problems of an agglomeration planning.

\section{Results and Discussion}

If the internal migration is viewed through the lens of housing aspects, then it is a change in the ways, models of citizens' life with the obligatory change of housing located in more than one city or town [11]. The availability of affordable, decent and environmentally friendly housing in a prosperous region attracts migrants and at the same time serves as a reason for the permanent abode of local citizens. And as the reverse process, a limited, for any reason, access to a decent housing in the proposed area leads to a sharp decrease in migration to this area and, moreover, increases the outflow of the population from the area [12]. Thus, there is a relationship between the dynamics of the migration flow and disproportionate housing conditions at the point of residence and arrival. More appropriate hypotheses to explain this situation is the following: the smaller the number of the population needs internal migration, the more closely it is connected with living conditions. A decent housing and living conditions are an essential factor for returning to the home area. This means that people satisfied with their living and environmentally friendly living conditions on the spot do not seek to change their place of residence. Thus, the demographic effect of "ageing-in-place" is manifested in a favorable natural environment.

However, in the context of independent Kyrgyzstan, the internal migration, which varies around $25 \%$, has caused an unregulated urban growth, especially in the capital Bishkek. Thereby putting at serious risk a systematic and predictable development of the capital, a demographic development of waste regions, an agrarian potential of villages, villages and other settlements [13].

The state policy of Kazakhstan towards the capital Nur-Sultan can serve as an example of an organized migration flow. The dynamics of the numerical and the urban population there has increased dramatically, but at the same time the volume of housing construction and infrastructure support to the social objects is closely linked to the dynamics of growth of internal migrants. In general, it is an effective program for the movement of citizens from a region with a surplus of labor force to the rapidly developing urbanized center of the country. Such a centralized migration policy ensured social stability and economic growth through the proportional distribution of labor and production resources [14].

In Kyrgyzstan due to the absence of systemic state regulation of housing construction and demographic policy, the capital's authorities did not have the opportunity to fully respond to the modern challenges of migration flows. The authorities did not fully appreciate the scale of the migration mobility of their compatriots.

In this way, new housing estates have become hotbeds of social instability and environmental danger. The source of instability was represented by the issues of inadequate 
provision and maintenance of migratory housing estates with infrastructural and socially significant facilities. Household waste and the exploitation of natural resources are not regulated by a centralized system, which leads to an unfavorable environmental situation in the new housing estate. It turns out, as if they live in the capital, but at the same time do not have basic living conditions, since there are no schools, hospitals, clinics, kindergartens, shopping centers and there are electricity, water and roads in some housing estates. City service organizations refuse to provide them with services due to a systemic collapse. Infrastructure facilities of some new buildings do not meet the needs of this residential area. Meanwhile, many residents already have all permits for residence and construction in the metropolitan area.

The current situation in Bishkek reflects that the existing housing problems in the context of the demographic growth of the population have begun to negatively affect the quality of life of all citizens. It became obvious that the entire engineering and social infrastructure of the city is under excessive pressure, because it wasn't designed for such intensive work, and requires an early remodeling.

Recently, the capital has been struggling to cope with car traffic, the work of urban utilities is wearing out quickly, social facilities cannot cope with the increasing flow of people, and the migration wave not only does not subside, but is also difficult to control. The pace of construction of socially significant and housing facilities doesn't meet the consumer needs of the population.

But the danger of unregulated development of suburban migrant settlements cannot be underestimated. Such concepts as "uncontrolled areas", "black belt", "shahid's belt", "disadvantaged belt" and similar names appeared as a result of active internal migration not controlled by the state. Some migratory settlements appeared with the tacit consent of the state, others out of objective social necessity in order to meet their needs with minimal financial resources. As a result, households are organized around the capital that cannot afford expensive housing within the city.

Today, therefore, due to the active internal migration it is an important task not only to develop migratory residential areas and small towns, but also to organize a modern residential area - the formation of a modern Bishkek agglomeration.

It is not a secret that the core problem of Bishkek is the territorial restriction in the expansion of the city due to the natural landscape. There are many well-grounded opinions about not expanding the construction zone, but finding ways to build higher-rise buildings, including residential complexes. However, such a decision only postpones the decision to expand the city's territory, but in general doesn't solve the issue of providing citizens, especially migrants, with housing space. With the expansion of the boundaries of the urban area, it is necessary to modernize management activities with a certain delegation of authority.

It is important to note that the internal migration situation continues to this day, this trend began in 1989. The problem of internal migration lies in the disproportionate development of the country's regions [15]. So, since then, more than 50 new housing estates have been organized by migrants around Bishkek. In most of them social facilities and engineering communications haven't yet been built. This is indeed a violation of citizens' rights to own decent and affordable housing.

At the same time, the statement that such characteristics are inherent in all new buildings is absolutely erroneous. Among the new housing estates, there is a clear distribution of them according to the profitability of the homeowners themselves. Basically, the differentiation by value is based on the geographical and climatic location of the settlement [13]. The owners of housing located in new buildings in the southern part of the capital, which is considered more expensive and prestigious, are citizens with high incomes. And, conversely, individual new buildings in the northern part of the capital, mainly the middle and lower middle stratum 
of the population live, with the exception of some households. The overwhelming majority of internal migrants settle down precisely among the poor housing estates.

If at the beginning of the active period of self-development in residential new buildings housing was mainly built by city dwellers, then in subsequent years these lands for individual housing became attractive for rural migrants. At the same time, it is difficult to track the number of internal migrants, due to the lack of a systematic registration of the living in migration areas.

According to R. Salmorbekova (2010) and N.A. Israilov (2010) the residential areas are home to $250.0-300.0$ thousand people [9]. The situation is aggravated by the fact that some dwellings haven't been commissioned, so residents cannot register here and obtain a legal status.

Thus, the urban area has increased by 2,500 hectares due to the last 24 migratory areas. The supply of water there is $37.0 \%$, electricity $-56.0 \%$, roads $-57.0 \%$. Let us especially note the problems of the "Ala-Archa" housing estate, housing was built near the "sarcophagus", where the carcasses of animals infected with dangerous diseases, such as foot-and-mouth disease, anthrax and so on, were disposed of. Accommodation is not permitted within a 500meter radius.

The residents of migration settlements don't have an access to important socially significant services. For example, due to the lack of numbering or names of streets and house numbers, it is not possible to call an emergency medical assistance. Only in 18 large new buildings there are full-fledged schools, and in new housing estates there are no secondary schools at all, and therefore $7.0 \%$ of children living in such new buildings don't attend school on a regular basis. Meanwhile, the existing schools in that area are a three-fold overcrowding, the school is designed for 380 students, but over 1000 is studying and children sit down for 3 children at one desk [16].

According to the statistics of the Kyrgyz Republic, $74.4 \%$ of migrants are between the ages of 25-60. At the same time, 16.5\% came from Naryn region, 5.4\% from Issyk-Kul region, 5.5\% from Talas region, 9.4\% from Jalal-Abad region and 11.5\% from Osh region. The reasons for migration were the unemployment $-41.2 \%$, future prospects $-23.1 \%$, standard of living $-12.1 \%$, education $-11.6 \%$ and family circumstances $-9.6 \%$ [17].

According to the theory of territorial organization of the migrant population by J. Gibbs, A. Lesh, W. Izard [18], today's capital of Kyrgyzstan belongs to the fourth class of urbanization, there is an active movement of the population to large cities with a simultaneous demographic failure in smaller settlements.

However, there is an undesirable feature of urbanization - the excess concentration of migrants, local population and other people in the capital. More than $20.0 \%$ of the total population lives in Bishkek. Nowadays the population of Bishkek, according to independent experts, is about 1.4 million people with a total population of more than 6.5 million people. Taking into account the growth of the population by $2-3 \%$, the forecast of the city's population in 25 years will be more than 2.5 million citizens [19].

The concept of the so-called discontinuous/continuous spatial development is proposed with such growth rates of Bishkek. It refers to the discontinuity of the living environment with the continuity of communications and the natural environment. This form of spatial growth of the city is attractive, firstly, by the preservation and implementation of natural resources between residential formations, and secondly, by an increase in the speed of movement depending on the frequency of necessary stops of high-speed public transport [19].

The versatile structure of the capital is attractive for its importance for future expansion, using various technical and planning solutions and with the possibility of correlating with the surrounding natural and ecological conditions [20]. The capital's scheme has a significant land reserve without active development of any real estate objects. The improvement of the structural scheme of the city will occur due to a gradual increase in the functional saturation 
of residential and recreational spaces. And the roads and railways must ensure the accessibility of the main functional areas of the capital and nearby microdistricts. Such an urbanistic scheme makes it possible to organically combine the natural discontinuity of urban construction and the compactness of individual migratory settlements.

It is important to note that the combined and diverse structural scheme of the future development of the agglomeration affects the planning of the landscape environment, engineering communications, control and planning of the demographic situation and sociocultural planning.

The spatial expansion of the city and migratory housing estates within the framework of the chosen urban planning model will allow the city's growth to "loop back", redirecting it to large-scale development. At the same time, new inconvenient territories will be developed, and the looking, diagonal-toothed form of the city plan will gradually be been modernized into a multidirectional model [19].

\section{Recommendations and Conclusion}

It is proposed to create the Administration of the Bishkek agglomeration with the purpose of centralized and systemic management of the construction of all objects. Further, it is recommended to transfer to the administration the authority to regulate and manage migration housing estates. The Bishkek agglomeration should become the main source of housing distribution and the center of the country's economic development. Alternative district administrations will manage migration flows around cities - satellites of the agglomeration.

Due to such model of agglomeration, it is assumed that the growth of the capital's city dwellers will decrease by $25.0 \%$ and the corresponding growth in the population of satellite cities and migratory residential areas of the agglomeration will take place. The transit traffic through the city of Bishkek will sharply decrease and the growth rate of private vehicles will decrease by $50 \%$. The ecological situation in the capital will significantly improve due to the transfer of industrial zones outside the city and their placement in close proximity to the international transport and air corridor [19].

By studying the problems of individual migratory buildings and constructions, the following difficulties were identified: problems of access to and/or lack of quality drinking water, problems of asphalt roads and sidewalks, lack of socially significant educational and public facilities, lack of public hospitals and clinics, absence of recreation and sports leisure centers. Such shortcomings in migration areas create unequal social conditions for migrants and city residents.

With regard to the relationship between the rate of migration and the housing conditions, there is a close relationship between private home ownership and migration. In particular, private homeowners are less willing and inclined to leave their homes than tenants. The main reason for not moving is that the cost of housing in the regions is much lower than in the capital. And also, the costs of moving for homeowners are much higher than for tenants. In this regard, the younger generation is prone to migration than the older settled household. Therefore, the projects of attracting migrants to areas with a shortage of labor resources through affordable and high-quality housing are interesting.

The reorientation of a large city and adjacent settlements towards the formation of an agglomeration and the determination of the legal status of satellite cities is a natural result of development, which manifests itself in compliance with the functional structure of an agglomeration with its changing needs. The development of the agglomeration sets the goal of not only increasing the scale of development, but also improving the quality of life of the population as a whole.

The depressed residential areas of the future agglomeration will revive due to the development of a network of railways and highways. Such transport logistics routes will 
create a single territorial and market system and increase the mobility of the population. The construction and expansion of the agglomeration is a large and attractive investment object. The entire agglomeration project can be recognized as a desirable investment potential for foreign investors [21]. In order to maintain the attractiveness of the agglomeration, it is necessary to build and launch production facilities with appropriate infrastructure facilities.

It should be noted that the proportional regional development of the country reduces the rate of oriented migration and thereby reduces the demographic burden on Bishkek and its suburbs. The creation of an agglomeration will make it possible to control the number of residential new buildings, the number of migrants and the level of social benefits in them.

The listed circumstances determine the need to expand the state policy aimed at solving the problems associated with oriented internal migration. It is necessary to strengthen the implementation of measures taken by the state bodies and agencies aimed at optimizing and regulating migration processes from the regions of the country.

\section{References}

1. A. B. Asylbaev, Bull. of the Taj. Nat. Univ, 2/4-2, 6 (2017)

2. C. H. Mulder, Demographic Research, 15, 401 (2006)

3. C. H. Mulder, H. Clara H., and J. C. Thomas, Population, Space and Place, 15(4), 299 (2009)

4. T. De Vroome, F. Van Tubergen, International Migration Review, 44(2), 376-403 (2010)

5. A. N. Asaul, G. V. Kumskov, M. T. Kasymova et al., Economics and property management: a textbook for universities in Bishkek, 428 (2012)

6. A. N. Asaul, M. A. Asaul, P. B. Lyulin, N. V. Chepachenko, Problems of forecasting, 3(174), 111 (2019)

7. K. Isaev, S. Borsokbaeva, Population: Quality of life and health, 94 (2002)

8. G. V. Kumskov, A. B. Asylbaev, K. N. Niyazalieva, Bull. of the Taj. Nat. Univ. 2/3, 87 (2017)

9. R. Salmorbekova, N. A. Israilova, Social tension in modern Kyrgyzstan, 31 (2010)

10. U. Zh. Ergeshbaev, Scientific research in the Kyrgyz Republic, 1, 22 (2020)

11. A. B. Asylbaev, K. N. Niyazalieva , A. Bakasov, Bull. of the Kyr.-Russ. Slav. Univ., 18(11), 8 (2018)

12. A. B. Asylbaev, Bull. of the Taj. Nat. Univ, 2/4, 6 (2017)

13. A. B. Asylbaev, Competitiveness in the global world: economics, science, technology, 10(57), 134 (2017)

14. K. B. Asylbaev, A. B. Asylbaev, K. N. Niyazaliva, Actual problems of economics. 180(6), 231 (2016)

15. A. B. Asylbaev, K. N. Niyazalieva, Bull. of the Taj. Nat. Univ, 3, 15 (2018)

16. A. B. Asylbaev, Bull. of the Kyr.-Russ. Slav. Univ., 15(1), 97 (2015)

17. National Statistical Committee of the Kyrgyz Republic, the Ministry of Health [Kyrgyz Republic] and the ICF International, Demographic and Health Survey of the Kyrgyz Republic 2012, 488 (2013)

18. The main patterns of the development of urbanization. The theory of J. Gibbs, A. Lesch, W. Izard. 
19. M. Kurmanbekova, B. Asanakunov, S. Dresvyannikov, The concept of the formation and development of the Bishkek agglomeration and adjacent city. http://analitika.akipress.org.

20. T. I. Turdiev. Financial analytics: problems and solutions, 7(289), 17 (2016)

21. Yu. A. Levin, A. M. Platonov, Economy of region, 16(3), 884 (2020) 